\title{
Mechanisms Underlying Transition from Acute Glomerular Injury to Late Glomerular Sclerosis in a Rat Model of Nephrotic Syndrome
}

\author{
Sharon Anderson, ${ }^{\star}$ Jonathan R. Diamond, ${ }^{\mathbf{5}}$ Morris J. Karnovsky, ${ }^{5}$ and Barry M. Brenner* \\ With the technical assistance of L. E. Clarey, S. J. Downes, S. L. Riley, K. J. Sandquist, and J. L. Troy \\ ${ }^{*}$ Renal Division and Department of Medicine, Brigham and Women's Hospital, Boston, Massachusetts 02115; ${ }^{\ddagger}$ Department \\ of Medicine, New England Deaconess Hospital, Boston, Massachusetts 02215; and \$Department of Pathology \\ and the Harvard Center for The Study of Kidney Diseases, Harvard Medical School, Boston, Massachusetts 02115
}

\begin{abstract}
Functional and morphologic measurements were performed in Munich-Wistar rats after a single central venous injection of puromycin aminonucleoside (PA) or saline vehicle (sham). During phase I, PA rats exhibited overt nephrotic syndrome and impaired glomerular filtration, primarily due to a reduction in the glomerular capillary ultrafiltration coefficient. The morphologic counterpart of the latter consisted of effacement of glomerular epithelial cell foot processes and decrease in the number of filtration slit diaphragms. Administration of the angiotensin I converting enzyme inhibitor (CEI) enalapril to PA rats did not ameliorate glomerular dysfunction. During phase II, PA rats exhibited spontaneous resolution of proteinuria, impaired function, and morphologic abnormalities. However, PA rats now demonstrated marked glomerular capillary hypertension and continued, albeit lesser, reductions in the ultrafiltration coefficient. Concurrent CEI administration modestly lowered systemic arterial pressure, and normalized the glomerular capillary hydraulic pressure and ultrafiltration coefficient. Additional rats were studied during phase III, 70 wk after injection. In PA rats, prior glomerular hypertension was associated with development of recurrent proteinuria and extensive glomerular sclerosis, whereas concurrent CEI administration limited these parameters to values comparable to those in sham rats. Glomerular hypertension thus may explain the development of glomerular sclerosis and renal failure long after an episode of acute glomerular injury.
\end{abstract}

\section{Introduction}

Although acute glomerular injury has been extensively investigated, few studies have examined the mechanisms involved in the transition from the acute injury phase to the later development of glomerular sclerosis and loss of renal function. A potentially revealing model of evolving glomerular injury has recently been reported by Diamond and Karnovsky (1). A single jugular venous injection of puromycin aminonucleoside

Portions of these studies were presented at the 19th Annual Meeting of the American Society of Nephrology, Washington, DC, 1986, and the Xth International Congress of Nephrology, London, 1987, and were published in abstract form (1987. Kidney Int. 31:379 [Abstr.]).

Received for publication 18 November 1987 and in revised form 21 June 1988.

J. Clin. Invest.

(c) The American Society for Clinical Investigation, Inc.

$0021-9738 / 88 / 11 / 1757 / 12 \$ 2.00$

Volume 82, November 1988, 1757-1768
$(\mathrm{PA})^{1}$ in Sprague-Dawley rats results in massive proteinuria and overt nephrotic syndrome lasting 2-3 wk. Thereafter, a recovery phase occurs, during which the nephrotic syndrome abates spontaneously, and protein excretion falls to near normal levels. After a period of months, however, without further PA injection, proteinuria recurs, and is accompanied by the development of glomerular sclerosis (1-4).

Previous studies have implicated hemodynamic factors in the pathogenesis of glomerular sclerosis in various models of glomerular injury that are characterized by single nephron hyperfiltration, hyperperfusion, and hypertension (5-10). In other circumstances, however, renal insufficiency and glomerular sclerosis eventuate in the absence of any phase of single nephron hyperfiltration. Impaired single nephron filtration is the rule in experimental glomerulonephritis (11-14), and also presumably in clinical glomerulonephritis. In some circumstances, episodes of clinical glomerulonephritis may be followed by a lengthy period of relatively quiescent disease, without ongoing immunologic activity, which is nonetheless followed by late deterioration of renal function (15). Accordingly, the purpose of this study was to characterize the sequential functional and structural parameters in a triphasic model of renal injury, and particularly to evaluate the potential hemodynamic contribution, and possible beneficial effect of pharmacologic therapy, to the late sequellae of glomerular injury.

\section{Methods}

Three groups of adult male Munich-Wistar rats, with initial weights of 220-260 g, were studied. Under Brevital anesthesia ( $50 \mathrm{mg} / \mathrm{kg}$ i.p.), the right jugular vein was cannulated and injected with either $3 \mathrm{ml}$ of saline vehicle (sham) or $50 \mathrm{mg} / \mathrm{kg}$ PA (Sigma Chemical Co., St. Louis, MO) dissolved in $3 \mathrm{ml}$ of saline, given as a single injection over 3 min (1). All rats received standard rat chow. Half the PA-injected rats received no therapy, and half (designated PA/converting enzyme inhibitor [CEI]) were treated with the angiotensin I CEI, enalapril (Merck, Sharp \& Dohme, West Point, PA), at a dose of $50 \mathrm{mg} /$ liter in the drinking water starting 1 wk before PA injection. The enalapril dose was raised to $100 \mathrm{mg} /$ liter in the latter part of the study to provide continuing blood pressure control as body weight increased.

1. Abbreviations used in this paper: $\overline{\mathrm{AP}}$, mean arterial pressure; $\mathrm{CEI}$, converting enzyme inhibitor; FF, filtration fraction; GFR, glomerular filtration rate; Hct, hematocrit; $K_{\mathrm{f}}$, glomerular capillary ultrafiltration coefficient; PA, puromycin aminonucleoside; PAH, para-amino hippurate; PAS, Periodic acid-Schiff; PRC, plasma renin concentration; $\overline{\mathbf{P}}_{\mathrm{GC}}$, mean glomerular capillary hydraulic pressure; $\overline{\Delta \mathrm{P}}$, mean glomerular transcapillary hydraulic pressure gradient; $\pi_{\mathrm{A}}$, afferent arteriolar colloid osmotic pressure; $\mathrm{Q}_{\mathrm{A}}$, glomerular capillary plasma flow rate; RPF, renal plasma flow rate; SBP, systolic blood pressure; SN, single nephron; $U_{\text {prot }} V$, 24-h urinary protein excretion rate. 
Part I: acute phase studies. Pilot studies established that this PA regimen produced overt nephrotic syndrome during the first 1-3 wk after injection. Further evaluation of the nephrotic syndrome was performed in three groups of rats (sham, PA, and PA/CEI, each $n$ $=10-11) .2 \mathrm{wk}$ after injection, rats were placed in metabolic cages and 24-h urine collections were obtained for determination of protein excretion $\left(U_{\text {prot }} V\right)$ rates. $4 \mathrm{~d}$ later, the rats were fasted overnight, and the next morning tail venous blood was obtained for determination of serum cholesterol and triglyceride levels. Approximately $4 \mathrm{~d}$ later, the rats were decapitated and trunk blood was collected for determination of serum albumin level and plasma renin concentration (PRC).

Three additional groups of rats (each $n=5-9$ ) underwent renal function studies during the acute nephrotic syndrome. At 2 wk after injection, sham and PA rats underwent measurements of whole kidney and glomerular hemodynamics, as described below. PA/CEI rats underwent measurement of whole kidney parameters only. Immediately after the functional studies, the kidneys were perfusion fixed for morphologic examination as described below.

Part II: recovery phase studies. Identical protocols for characterization of systemic parameters were carried out in three similarly prepared groups of rats (each $n=11-12$ ) studied 8-10 wk after injection, after resolution of renal insufficiency and nephrotic syndrome. Another three groups of similarly prepared rats (each $n=8-9$ ) then underwent micropuncture studies at 8-10 wk, after which the kidneys were perfusion fixed for morphologic examination.

Further studies were performed in 10 additional rats that had received PA injections 8-10 wk previously, to investigate the role of angiotensin II as a hemodynamic mediator in phase II. In half the rats, micropuncture measurements were performed under baseline conditions, after which an intravenous infusion of the angiotensin II receptor antagonist saralasin was begun at a rate of $0.3 \mathrm{mg} / \mathrm{kg}$ per h. $30 \mathrm{~min}$ later, during the continuous infusion, micropuncture measurements were repeated. The remaining rats received a normal saline infusion and served as time controls.

Part III: chronic phase studies. Three additional groups of rats (each $n=8-13$ ) were followed for 70 wk after injection, with monthly determinations of $U_{\text {prot }} \mathrm{V}$ and systolic blood pressure (SBP) by the tail cuff method (16). At $70 \mathrm{wk}$, renal function studies were performed in some of the rats, and all rats were killed for morphologic examination.

Micropuncture studies. Rats were anesthetized with $100 \mathrm{mg} / \mathrm{kg}$ i.p. Inactin and placed on a temperature-regulated table. The left femoral artery was catheterized, and a baseline collection of $0.28 \mathrm{ml}$ of blood was obtained for measurement of plasma sodium, potassium, and hematocrit (Hct). This arterial catheter was used for subsequent periodic blood sampling and estimation of mean arterial pressure $(\overline{\mathrm{AP}})$ via an electronic transducer connected to a direct-writing recorder. After tracheostomy, venous catheters were inserted for infusions of inulin, para-amino hippurate (PAH), and plasma. Intravenous infusions of rat plasma, and $4-10 \%$ inulin solution with $1.5-4 \% \mathrm{PAH}$ in $0.9 \% \mathrm{NaCl}$, were started at rates of 6.0 and $1.2 \mathrm{ml} / \mathrm{h}$, respectively. The lower concentrations of inulin and PAH were used in the nephrotic rats, with renal insufficiency, to ensure appropriate plasma concentrations of these substances. The left kidney was exposed and suspended on a lucite holder, and its surface was illuminated and bathed with isotonic saline. The left ureter was catheterized for urine collections.

As the plasma volume of rats prepared for micropuncture is reduced by $\sim 20 \%$ (17), euvolemia was maintained using the following protocol. Isoncotic rat plasma was infused at $0.1 \mathrm{ml} / \mathrm{min}$ in a total amount equal to $1 \%$ of the body weight, followed by a reduction in infusion rate to $1.6 \mathrm{ml} / \mathrm{kg}$ per $\mathrm{h}$, to maintain the Hct constant. Sham rats received normal plasma, and PA rats received plasma from nephrotic rats that had been injected with PA 2 wk previously.

For calculation of single nephron (SN) glomerular filtration rate (GFR), exactly timed samples of tubule fluid were collected for determination of flow rate and inulin concentration. Samples of efferent arteriolar blood were obtained for determination of protein concentration. Coincident with these collections, $0.21 \mathrm{ml}$ of arterial blood was obtained in each period for determination of Hct and plasma concen- trations of inulin, PAH, and protein, and 15-40-min urine collections were obtained for determination of flow rate and inulin and PAH concentrations. These measurements permitted calculation of GFR (inulin clearance) and renal plasma flow (RPF) (PAH clearance) by standard formulas. Time-averaged hydraulic pressures were measured in surface glomerular capillaries, proximal tubules, and efferent arterioles with a servo-null micropipette transducer system (Instrumentation for Physiology \& Medicine, San Diego, CA). In nonnephrotic rats, colloid osmotic pressure of plasma entering and leaving glomerular capillaries was estimated from values for protein concentration in femoral arterial (representing afferent arteriolar) and efferent arteriolar plasma samples using the equation derived by Deen et al. (18). These estimates of pre- and postglomerular plasma protein concentration permit calculation of $\mathrm{SN}$ filtration fraction (FF), glomerular capillary ultrafiltration coefficient, and afferent and efferent arteriolar blood flow rates and resistances, using equations previously described (18). In nephrotic rats, lipemic serum renders this protein determination method inaccurate, and therefore FF in nephrotic rats was derived from inulin and PAH clearances. For purposes of consistency, SNFF in all phase I rats was calculated from inulin and PAH clearances, corrected for PAH extraction. Arterial albumin concentration was determined by radial immunodiffusion (19), total protein was calculated using measurements of the albumin/globulin ratio derived from serum protein electrophoresis, and efferent arteriolar protein concentration was calculated from these measurements. Values for arterial and efferent arteriolar colloid osmotic pressures were then calculated using equations recently derived for nephrotic rats (20).

Morphology. Kidneys were perfused via an infrarenal aortic cannula with $0.1 \mathrm{M}$ cacodylate buffer containing $5 \%$ sucrose (pH 7.4) for 2-3 min, followed by $2 \%$ glutaraldehyde in $0.1 \mathrm{M}$ cacodylate buffer for 1-2 min. Both kidneys were removed, sectioned coronally, and immersed in $2 \%$ glutaraldehyde in cacodylate buffer for an additional $2 \mathrm{~h}$. After fixation, 1-2-mm cortical sections were prepared from coronal sections and, along with the midcoronal sections, rinsed for $2 \mathrm{~h}$ in 0.1 $M$ cacodylate buffer with 5\% sucrose (pH 7.4), embedded in Epon, and prepared for light and electron microscopy. Thick sections, approximately $1 \mu \mathrm{m}$, were stained with $1 \%$ toluidine blue, a modified polychrome stain (21), or phosphotungstic acid-hematoxylin, and viewed with a Leitz photomicroscope. Thin sections $(60-80 \mathrm{~nm})$ were stained with $4 \%$ aqueous uranyl acetate and lead citrate, and examined with an AEI electron microscope. Midcoronal sections of the whole kidney were embedded in paraffin, treated with sodium borohydride (22), and then stained with periodic acid-Schiff (PAS) or phosphotungstic acidhematoxylin.

Mesangial foam cells were defined as mesangial cell nuclei surrounded by cytoplasmic fat vacuoles, which are Oil Red $O$ positive in frozen section. Mesangial cellularity was assessed by counting the number of cell nuclei in each mesangial region, with nuclear counts greater than three per region considered to represent segmental mesangial hypercellularity. A mesangial region was defined as that mesangial area corresponding to an adjacent capillary loop, as viewed at high magnification $(\times 40)$. Glomerular sclerosis was defined as loss of cellular elements from the capillary tuft, collapse of the capillary lumina, and folding of the glomerular basement membrane with entrapment of amorphous material. Hyalinosis was defined as rounded or crescentshaped foci of strongly eosinophilic material on PAS staining, usually subendothelial in location, which occurred in the capillary tuft with or without the sclerotic changes. On average, 345 glomeruli per animal were evaluated and the percentage of sclerotic glomeruli was expressed as a percentage of the total number of glomeruli counted.

Analytical. The volume of fluid collected from individual proximal tubules was estimated from the length of the fluid column in a constant bore capillary tube of known internal diameter. The tubule fluid inulin concentration was measured by a microfluorescence method (23). Inulin concentrations in plasma and urine were measured using a macro-anthrone method (24), and PAH concentrations were measured by the method of Smith et al. (25). Protein concentrations in nonnephrotic rats were determined using the fluorometric method 
developed by Viets et al. (26). Urinary protein concentration was measured by precipitation with $3 \%$ sulfosalicylic acid (27). Sodium and potassium concentrations were measured by flame photometry. Serum albumin was measured using radial immunodiffusion (19). Cholesterol and triglycerides were measured using a colorimetric method (Sigma Chemical Co.). PRC was determined by incubating $0.1 \mathrm{ml}$ of rat plasma with $0.1 \mathrm{ml}$ rat anephric plasma and $0.4 \mathrm{ml}$ of $0.2 \mathrm{M}$ maleate buffer, $\mathrm{pH} 6.0$ at $37^{\circ}$ for $1 \mathrm{~h}$. Appropriate dilutions of rat plasma samples were made using Tris buffer. The generation of angiotensin I was then determined by RIA using commercially available reagents (New England Nuclear, Boston, MA).

Statistical. Statistical analysis was performed by unpaired $t$ test or one-way analysis of variance followed by computation of modified $t$ values and multiple pairwise comparisons according to the method of Bonferroni (28), as appropriate. Analysis of the two-period saralasin studies was performed using the paired $t$ test. Statistical significance was defined as $P<0.05$.

\section{Results}

\section{Phase I studies}

Characterization of the nephrotic syndrome. Central venous injection of PA produced an overt nephrotic syndrome and a mortality rate of $15-20 \%$ within the first 3 wk after injection. Surviving rats experienced dramatic weight gains of $50-80 \mathrm{~g}$, during which time edema and ascites were prominent. Laboratory evaluation further confirmed the presence of the nephrotic syndrome, as is demonstrated in the left panel of Table I. Values for body weight were slightly but not significantly higher in the PA rats at the time of killing. $U_{\text {prot }} V$, cholesterol, and triglycerides were markedly elevated in nephrotic rats, whereas values for serum albumin were severely depressed as compared with those in sham rats. This model thus mimics many aspects of the clinical nephrotic syndrome, and clearly represents a true nephrotic state, as contrasted with that seen with other PA dosage regimens, in which animals were not hypoalbuminemic $(11,12)$. Values for PRC were slightly but not significantly reduced in PA rats, whereas inhibition of angiotensin I converting enzyme was confirmed by markedly elevated values for PRC in those rats receiving CEI.

Serum protein electrophoresis measurements performed in sham $(n=5)$ and PA $(n=6)$ rats revealed significant reductions in both total protein (shams, $6.0 \pm 0.2 ; \mathrm{PA}, 4.3 \pm 0.2 \mathrm{~g} / \mathrm{dl}$ ) and albumin $(3.3 \pm 0.3$ vs. $1.1 \pm 0.1 \mathrm{~g} / \mathrm{dl})$ concentrations, thus resulting in a significantly decreased albumin/globulin ratio in the PA rats $(0.33 \pm 0.03)$ as compared with the sham rats
(1.2 \pm 0.1$)$. In the PA rats, values for the $\alpha_{1}$-globulin fraction were markedly elevated, $\alpha_{2}$ slightly increased, and the remaining fractions decreased, as compared with the sham rats.

Renal function studies. Whole kidney parameters in sham, PA, and PA/CEI rats studied at 2 wk are given in the left panel of Table II. Body weights were comparable in the three groups. Values for Hct and $\overline{\text { AP }}$ were comparable in sham and PA rats, but Hct significantly and $\overline{\mathrm{AP}}$ numerically lower in PA/CEI rats. The GFR was markedly and similarly depressed in PA and PA/CEI rats. Because values for RPF were only slightly lower in these two nephrotic groups, FF was markedly reduced. Note that renal extraction of PAH averaged $90 \pm 1 \%$ in sham rats, but was reduced in nephrotic rats, averaging only $50 \pm 7 \%$ in the latter. The nephrotic state resulted in electrolyte abnormalities, with PA/CEI rats exhibiting hyponatremia, and both nephrotic groups characterized by hyperkalemia and renal sodium retention, as compared with sham rats. Thus, phase $I$ is characterized by severe renal insufficiency, and administration of CEI had no ameliorative effect on indices of nephrotic syndrome or functional insufficiency.

Mean values for SNGFR, and the pressures, flows, and resistances governing glomerular ultrafiltration in sham and PA rats studied 2 wk after injection are summarized in the upper portion of Table III, and partially depicted in Fig. 1. Approximately $36 \%$ of the experiments begun in nephrotic rats could not be completed, due to hypotension, hypercoagulability precluding patency of vascular catheters, and/or respiratory insufficiency due to massive pleural effusions. These difficulties were particularly prominent in the relatively hypotensive PA/CEI rats, which were therefore not subjected to micropuncture study. Thus, only those rats (presumably the least compromised by the nephrotic syndrome) that were stable throughout the procedure were evaluated and reported here. In accord with previous micropuncture studies of PA (11, 12), values for SNGFR were markedly depressed in PA rats. $\mathrm{SN}$ hypofiltration in the nephrotic rats could not be attributed to a reduction in glomerular plasma flow rate $\left(Q_{A}\right)$, since these values were comparable in the two groups, resulting in a marked reduction in SNFF in the nephrotic rats. Nor were there any differences in the glomerular capillary hydraulic pressure $\left(\overline{\mathbf{P}}_{\mathrm{GC}}\right)$, proximal tubule and efferent arteriolar hydraulic pressures, or the mean glomerular transcapillary hydraulic pressure gradient $(\overline{\Delta P})$. Values for afferent, efferent, and total arteriolar resistances were also comparable in the two groups.

Table I. Summary of Systemic Parameters

\begin{tabular}{|c|c|c|c|c|c|c|}
\hline & \multicolumn{3}{|c|}{ Phase I } & \multicolumn{3}{|c|}{ Phase II } \\
\hline & Sham & PA & PA/CEI & Sham & PA & PA/CEI \\
\hline$n$ & 10 & 11 & 10 & 11 & 12 & 12 \\
\hline Body wt $(g)$ & $241 \pm 5$ & $249 \pm 4$ & $241 \pm 5$ & $319 \pm 5$ & $323 \pm 5$ & $312 \pm 4$ \\
\hline $\mathrm{U}_{\text {prot }} \mathrm{V}(m g / d)$ & $5 \pm 1$ & $112 \pm 17^{*}$ & $115 \pm 10^{*}$ & $8 \pm 1$ & $13 \pm 1^{*}$ & $10 \pm 1$ \\
\hline Cholesterol $(m g / d l)$ & $65 \pm 5$ & $240 \pm 15^{*}$ & $360 \pm 45^{* \neq}$ & $73 \pm 7$ & $88 \pm 5$ & $104 \pm 10^{*}$ \\
\hline Triglycerides $(m g / d l)$ & $61 \pm 5$ & $231 \pm 25^{*}$ & $240 \pm 19^{*}$ & $55 \pm 6$ & $73 \pm 5$ & $72 \pm 9$ \\
\hline Serum albumin $(g / d l)$ & $3.5 \pm 0.2$ & $1.3 \pm 0.1^{*}$ & $1.4 \pm 0.1^{*}$ & $3.7 \pm 0.2$ & $3.8 \pm 0.1$ & $3.6 \pm 0.1$ \\
\hline PRC (ng AI/ml per h) & $10.7 \pm 1.7$ & $8.8 \pm 1.0$ & $100.3 \pm 18.6^{* \pm}$ & $11.9 \pm 1.0$ & $7.4 \pm 0.8$ & $206.8 \pm 20.7^{* \neq}$ \\
\hline
\end{tabular}

Values are means \pm SEM. AI, Angiotensin I; other abbreviations as in footnote $1 . \quad * P<0.05$ vs. sham; ${ }^{\ddagger} P<.05$ vs. PA. 
Table II. Summary of Renal Hemodynamic Data

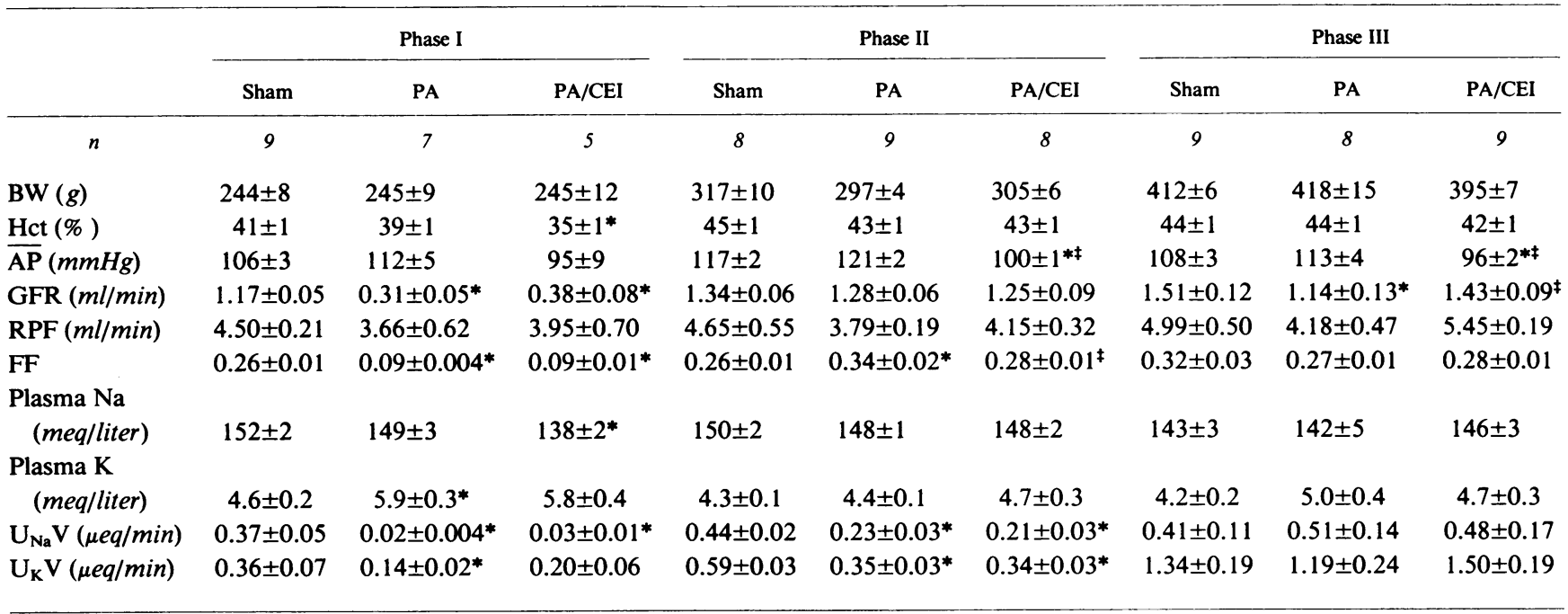

Values are means \pm SEM. BW, body weight; $U_{\mathrm{Na}} V$, urinary sodium excretion; $U_{K} V$, urinary potassium excretion; other abbreviations as in footnote $1 .{ }^{*} P<0.05$ vs. sham, ${ }^{\ddagger} P<0.05$ vs. PA.

Values for afferent and efferent arteriolar total plasma protein concentrations were significantly lower in the nephrotic rats. The highly abnormal albumin/globulin ratio resulted in significantly reduced values for afferent and efferent colloid osmotic pressures. Reduction of SNGFR in the nephrotic rats resulted primarily from a marked reduction in values for $K_{f}$, the glomerular capillary ultrafiltration coefficient, which averaged only $21 \%$ of that measured in sham rats $(P<0.001)$. Because all rats were in filtration pressure disequilibrium, unique values for $K_{\mathrm{f}}$ could be calculated. Although more extreme, this hemodynamic pattern of decreased SNGFR, SNFF, and $K_{\mathrm{f}}$ is similar to that reported in nonnephrotic rats administered lower doses of PA $(11,12){ }^{2}$

The role of reduced serum albumin and plasma oncotic pressure was further addressed in studies of four nephrotic rats which received normal plasma, rather than nephrotic plasma, to replace surgical losses during the experiment. In these rats, values for serum protein concentration were raised toward $(5.0 \pm 0.3 \mathrm{~g} / \mathrm{dl})$ although not to normal levels. Whereas values for SNGFR $(16 \pm 3 \mathrm{nl} / \mathrm{min})$ and $\mathrm{Q}_{\mathrm{A}}(110 \pm 27)$ remained comparable to those in the previously described rats, values for $\overline{\mathrm{P}}_{\mathrm{GC}}$ $(52 \pm 2 \mathrm{mmHg})$ and $\overline{\Delta \mathrm{P}}(39 \pm 1 \mathrm{mmHg})$ were slightly higher than those measured in sham rats (Table III).

Morphologic studies. Morphologic examination in phase I revealed normal glomerular and tubular architecture in sham rats (Fig. 2). Severe morphologic injury was evident in the PA rats. As is illustrated in Fig. 3, these morphologic abnormali-

2. In sham rats, reported values varied only slightly from those calculated with SNFF determined by standard methods (afferent and efferent arteriolar protein concentrations), and in no parameter did calculation method change statistical differences. Whole kidney FF range in sham rats was $0.25-0.33$; SNFF ranged from $0.24-0.34$ when determined by standard methods. In PA and PA/CEI rats, FF ranges were $0.07-0.10$ and $0.06-0.12$, respectively. By any calculation method, the markedly reduced values for SNGFR and FF in nephrotic rats yield values for $\mathrm{Q}_{\mathrm{A}}$ that are comparable, and values for $K_{\mathrm{f}}$ that are markedly reduced, as compared with those in sham rats. ties included glomerular visceral epithelial cell bleb formation and vacuolization, mild mesangial expansion, and mesangial foam cell accumulation. Areas of tubule collapse, tubule dilatation and cast formation, and interstitial edema were also evident. Transmission electron microscopy revealed extensive spreading of foot processes, as described in previous studies of PA (29). Morphologic appearance was not appreciably different between PA and PA/CEI rats.

\section{Phase II studies}

Spontaneous resolution of the nephrotic syndrome. During phase II, at 8-10 wk after injection, all stigmata of the nephrotic syndrome had resolved in the PA and PA/CEI rats. As summarized in the right panel of Table $I$, values for body weight, serum triglycerides, and serum albumin were now indistinguishable in the three groups, though $U_{\text {prot }} V$ remained minimally elevated in PA rats, and serum cholesterol levels remained slightly elevated in PA/CEI rats. Values for PRC were slightly but not significantly reduced in PA rats, and markedly elevated in PA/CEI rats.

Renal function studies. Phase II values for whole kidney parameters in sham, PA, and PA/CEI rats studied at 8-10 wk after injection are summarized in the middle panel of Table II. Average values for body weight and Hct were comparable among the groups. Mean arterial pressures were within the normal range and similar in sham and PA/CEI groups, whereas $\overline{\mathrm{AP}}$ was modestly but significantly lower in PA/CEI rats than in both other groups. Resolution of renal insufficiency was apparent, with values for GFR and RPF now comparable in all groups. However, in contrast to the findings in phase I, FF was now higher in the PA rats. This increased FF was not present in PA/CEI rats. Serum electrolytes were normal in all groups, whereas urinary sodium and potassium excretion remained slightly depressed in PA and PA/CEI rats.

Values for SNGFR and the hemodynamic determinants thereof in sham, PA, and PA/CEI rats studied during phase II are summarized in the bottom panel of Table III. In addition, the changes in SNGFR and its determinants that occurred 
between phases I and II are depicted in graphic form in Fig. 1. Recovery of single nephron function was evident, with values for SNGFR now comparable in all three groups. Values for $Q_{A}$ were also equivalent in the three groups. In marked contrast to the findings in phase I, however, PA rats exhibited striking glomerular capillary hypertension. Values for $\overline{\mathbf{P}}_{\mathbf{G C}}$ were markedly elevated in the PA rats, so that despite slight elevations in proximal tubule pressures, values for the glomerular transcapillary hydraulic pressure gradient, $\overline{\Delta P}$, were considerably higher than values measured in sham rats. As in previous studies using CEI therapy in experimental models of glomerular hypertension (8-10), concurrent CEI administration completely prevented the development of glomerular capillary hypertension, with values for $\overline{\mathbf{P}}_{\mathrm{GC}}$ in PA/CEI rats controlled to levels indistinguishable from those in sham rats. CEI administration also resulted in slight but significant elevations of SNGFR and $Q_{A}$ as compared with values in PA rats.

These values resulted from contrasting patterns in the intrarenal resistances. In the PA rats, values for afferent arteriolar resistance were comparable to those in sham rats, but values for efferent arteriolar resistance were significantly higher, thereby allowing a rise in $\overline{\mathbf{P}}_{\mathrm{GC}}$. In the PA/CEI rats, reduced values for afferent resistance were offset by a reduction in efferent arteriolar resistance as well, thereby maintaining $\overline{\mathbf{P}}_{\mathrm{GC}}$ within the normal range.

Values for afferent and efferent arteriolar plasma protein concentrations and colloid osmotic pressure were comparable in the three groups. Unique values for $K_{\mathrm{f}}$ were calculated in PA rats; in the sham and PA/CEI groups, only five of eight rats were in filtration pressure disequilibrium, so minimum values for these groups are presented. Values for $K_{f}$ in the PA rats, though somewhat recovered from the very low values observed during phase I (Fig. $1 B$ ), still remained well below those in Sham rats. Administration of CEI resulted in preservation of normal values for $K_{\mathrm{f}}$. Thus, elevations of $\mathrm{Q}_{\mathrm{A}}$ and $K_{\mathrm{f}}$ in the PA/CEI rats contributed to the slightly higher values for SNGFR as compared with the PA rats, despite the lower values for $\overline{\mathrm{P}}_{\mathrm{GC}}$ in the CEI-treated rats.

Because the intraglomerular hemodynamic pattern seen in PA rats during phase II was reminiscent of that produced by angiotensin II (30), and because chronic CEI therapy yielded a hemodynamic pattern that was consistent with suppression of angiotensin II, further studies of the potential role of this hormone in mediating these hemodynamic changes were performed with saralasin. As summarized in Table IV, infusion of saralasin into PA rats resulted in no change in $\overline{\mathrm{AP}}$, but in significant increases in whole kidney GFR and RPF, as well as in SNGFR and, numerically, in $Q_{A}$. In addition, acute saralasin administration resulted in near normalization of $\overline{\mathbf{P}}_{\mathrm{GC}}$ and a marked numerical increase in values for $K_{\mathrm{f}}$. Infusion of saline vehicle resulted in no changes in arterial pressure, GFR, RPF, or FF, and a slight reduction in SNGFR, rendering significant changes in intraglomerular hemodynamics unlikely.

Morphologic studies. Morphologic examination at 8-10 wk again revealed normal structure in the sham rats. In PA rats, occasional glomeruli exhibited segmental areas of mesangial expansion and epithelial cell bleb formation, but glomeruli generally appeared normal, suggesting resolution of the morphologic changes seen during the acute nephrotic phase. Glomerular sclerosis was not present. Note, however, that PA rats exhibited persistence of the tubulointerstitial abnormalities seen at $2 \mathrm{wk}$, which were not present in sham rats. Transmis-

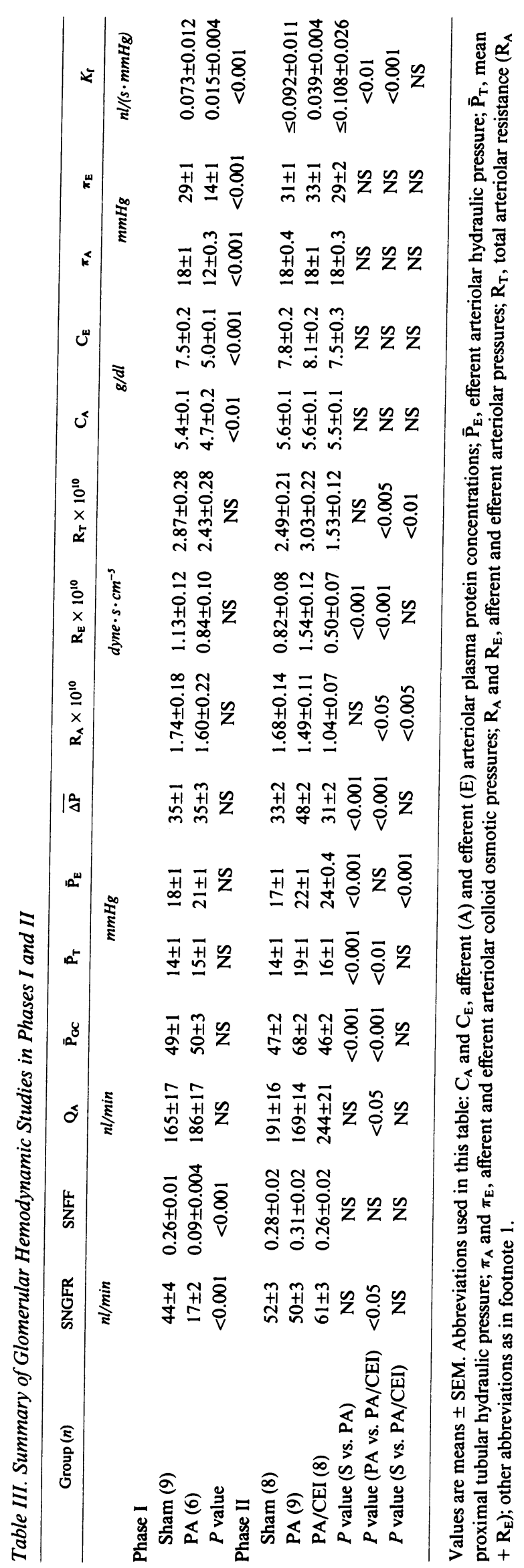




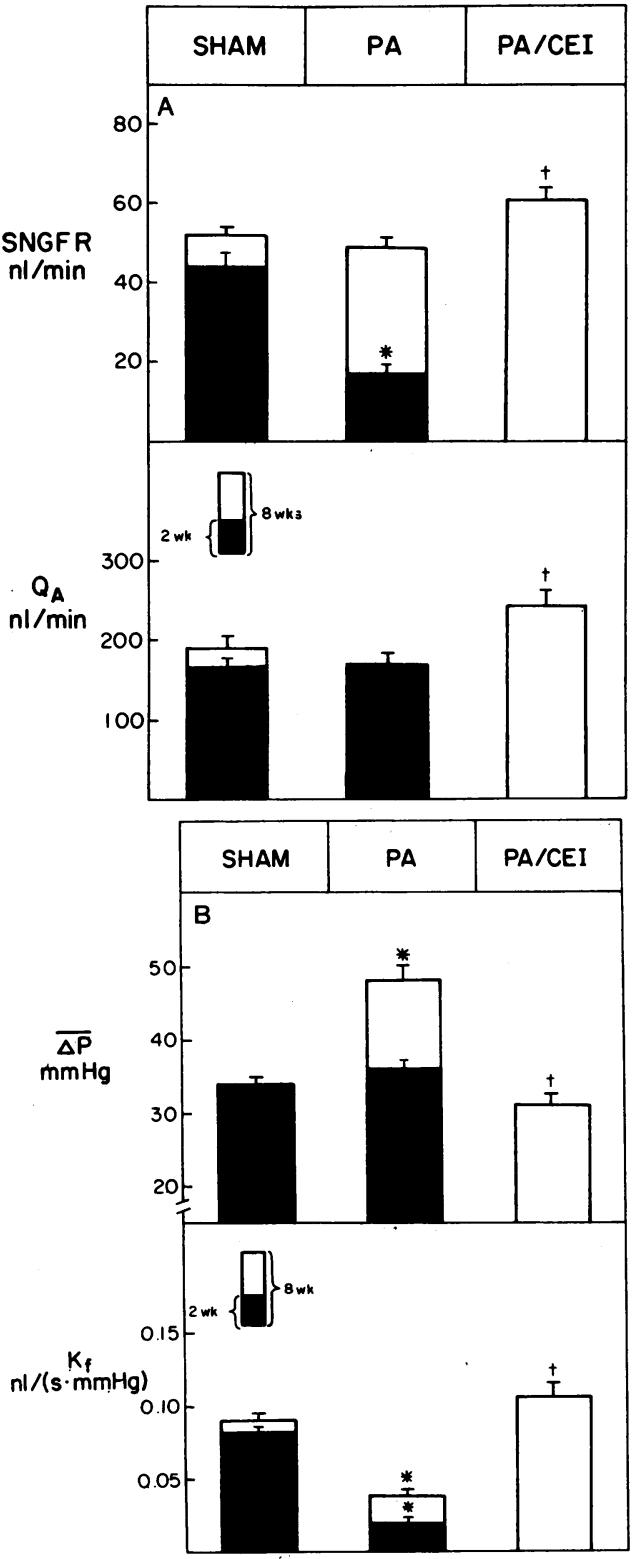

Figure 1. Summary of glomerular hemodynamic measurements during phases I and II. Solid bars depict values during phase I ( $2 \mathrm{wk}$ ) for the single nephron glomerular filtration rate (SNGFR) and glomerular capillary plasma flow rate $\left(\mathrm{Q}_{\mathrm{A}}\right)$ (Fig. $\left.1 A\right)$, and the glomerular transcapillary hydraulic pressure gradient $(\Delta \mathrm{P})$ and capillary ultrafiltration coefficient $\left(K_{\mathrm{f}}\right)($ Fig. $1 \mathrm{~B})$. Clear bars depict these values measured during phase II (8-10 wk), in sham, PA, and PA/CEI rats. During phase I, values for SNGFR were severely depressed in PA rats, due primarily to a marked reduction in $K_{f}$. In phase II, PA rats exhibited recovery of SNGFR, but also marked glomerular capillary hypertension and continued depression of $K_{\mathrm{f}}$, whereas concurrent CEI therapy normalized these parameters. Values are means \pm SEM. ${ }^{*} P<0.05$ vs. sham, ${ }^{+} P<0.05$ vs. $P A$ at same time point.

sion electron microscopy revealed no major areas of spreading of foot processes in any group. There were no differences between PA and PA/CEI rats.

\section{Phase III studies}

Serial measurements. Additional groups of sham, PA, and PA/CEI rats were followed for 70 wk after injection. As is

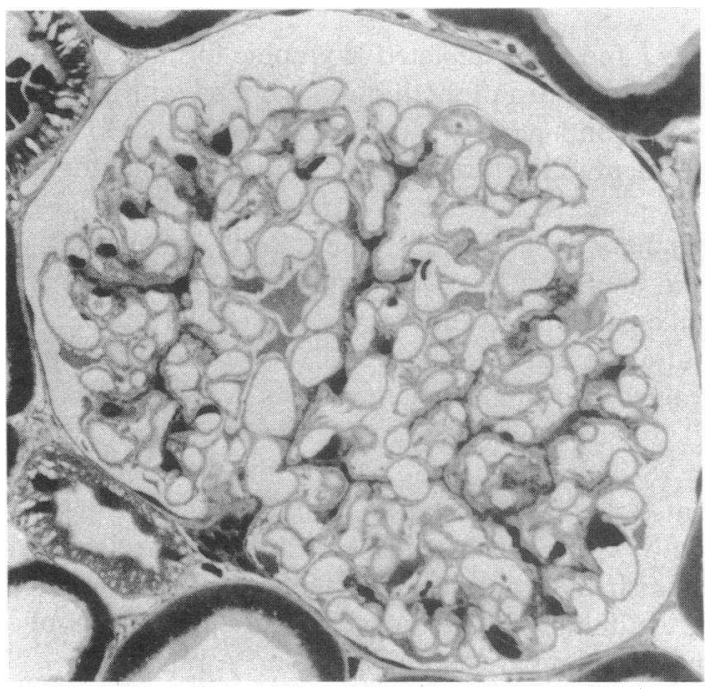

Figure 2. Light micrograph of renal cortex from sham rat during phase I. Glomerulus exhibits patent capillary loops, thin mesangial matrix, and normal visceral epithelial cells. (Toluidine blue, $\times 575$.)

depicted in the top of Fig. 4, serial measurements of SBP in the conscious state confirmed that this experimental model is not characterized by systemic hypertension, in that values for PA rats did not differ from those in sham rats at any time point. Values for SBP in the PA/CEI rats were generally lower, but only modestly and not always significantly reduced from those in the other groups. Time-averaged values for SBP throughout the entire study averaged $127 \pm 2 \mathrm{mmHg}$ in sham rats, $127 \pm 2$ $\mathrm{mmHg}$ in PA rats (NS), and $116 \pm 4 \mathrm{mmHg}$ in PA/CEI rats $(P$ $<0.05$ vs. both other groups). Serial measurements thus confirmed that PA rats remained normotensive, and that SBP values in PA/CEI rats were slightly lower, throughout the many months of observation.

. Serial values for $U_{\text {prot }} V$ measured during the three phases of injury are depicted in the bottom of Fig. 4. Values for $U_{\text {prot }} V$ were strikingly elevated in PA rats in phase I, and similar in PA/CEI rats. Thereafter, during phase $I I, U_{\text {prot }} V$ in both nephrotic groups declined to near normal levels, though values in PA rats remained slightly higher than those in sham rats. By 24 wk, $U_{\text {prot }} V$ in PA rats began to further diverge from the other groups, exhibiting a progressive rise over the duration of the study. In contrast, despite initial phase I injury which was as severe as that in PA rats, the development of recurrent proteinuria was completely prevented in PA/CEI rats, whose values for $U_{\text {prot }} V$ remained indistinguishable from those seen in sham rats. Thus, CEI administration had no discernible effect during the acute nephrotic syndrome, but normalization of $\overline{\mathrm{P}}_{\mathrm{GC}}$ and $K_{\mathrm{f}}$ by $\mathrm{CEI}$ during the phase of apparent recovery was associated with prevention of recurrent proteinuria during phase III.

Renal function studies. Values for renal hemodynamic parameters during phase III are summarized in the right panel of Table II. Values for body weight and Het did not differ among groups. Values for $\overline{\mathrm{AP}}$ were comparable in sham and PA rats, but slightly reduced in PA/CEI rats. Note that values for GFR were slightly but significantly lower in PA rats than in the other two groups. As in previous studies of aging in normal rats (31), weight gain in sham rats was not accompanied by a comparable increase in GFR, so that values for GFR/100 $\mathrm{g}$ 

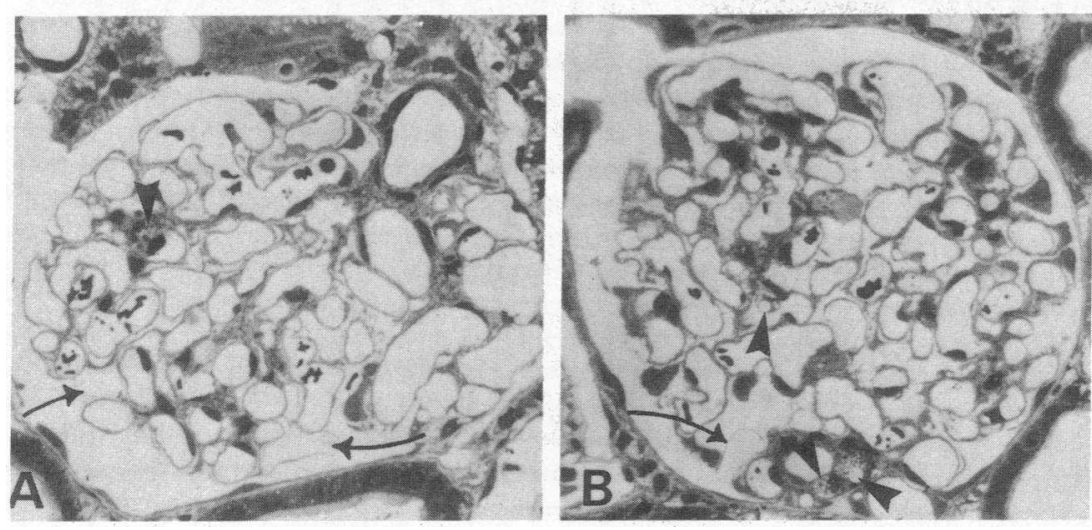

Figure 3. Light micrographs of glomeruli from PA rats during phase I. $(A)$ Glomerulus from PA rat demonstrating morphologic injury. Arrows indicate epithelial cell blebs. (Toluidine blue, $\times 510)$. (B) Glomerulus from PA rat. Arrow indicates epithelial cell bleb; arrowheads denote mesangial foam cells. (Toluidine blue, $\times 550$.)

body weight $(0.37 \pm 0.03)$ were lower than those measured in younger rats in phase II $(0.43 \pm 0.02)$. However, values for GFR/100 g body weight were even lower at 70 wk in PA rats $(0.27 \pm 0.03, P<0.05)$ than in sham rats, providing further evidence that recurrent proteinuria was accompanied by early signs of renal insufficiency. In contrast, values for GFR in absolute terms and in relationship to body weight in PA/CEI rats $(0.36 \pm 0.02, P<0.05$ vs. $\mathrm{PA})$ were comparable to those in sham rats, suggesting that amelioration of abnormal glomerular hemodynamic parameters in phase II resulted in protection against the development of renal insufficiency and proteinuria. There were no significant differences in RPF, FF, or serum and urinary electrolytes among the groups.

Finally, micropuncture measurements in small numbers of PA $(n=5)$ and PA/CEI $(n=6)$ rats indicated that the values for $\bar{P}_{\mathrm{GC}}$ that had been measured during phase II persisted during the $70 \mathrm{wk}$ of study. In phase III, PA rats exhibited continued glomerular hypertension, with values for $\overline{\mathbf{P}}_{\mathrm{GC}}$ averaging $65 \pm 1 \mathrm{mmHg}$, whereas glomerular hypertension remained absent in PA/CEI rats $(49 \pm 1, P<0.001$ vs. PA). Glomerular hypertension thus was sustained throughout the course of the study in PA rats, whereas CEI therapy resulted in complete and sustained prevention of glomerular capillary hypertension.

Morphology. Recurrent proteinuria in the PA rats was accompanied by significant morphologic injury. As is depicted in Fig. 5, both segmental and global glomerular sclerosis and hyalinosis were prominent in the PA rats. The former pattern was, by far, the more common one. There were no differences in degree of involvement between the outer cortical and juxtamedullary areas. Tubulointerstitial abnormalities, including fibrosis, were present in both PA and PA/CEI groups, though less severe in the CEI-treated rats. Quantitatively, individual values for the percent of glomeruli with sclerosis are depicted in Fig. 6. Sham rats exhibited a slight degree of glomerular sclerosis $(2.3 \pm 0.6 \%)$ due to normal aging, whereas glomerular injury was striking in PA rats, with $19.5 \pm 3.2 \%$ of glomeruli exhibiting sclerosis $(P<0.001$ vs. sham rats). In contrast, segmental sclerosis was found in only $4.3 \pm 0.6 \%$ of glomeruli in PA/CEI rats $(P<0.001$ vs. PA $)$, a value comparable to that seen in the aging sham rats that had never incurred renal injury. As is depicted in Fig. 7, linear regression analysis confirmed that values for $U_{\text {prot }} V$ predicted structural injury, with a clear correlation between values for $U_{\text {prot }} V$ and glomerular sclerosis in individual rats.

\section{Discussion}

These studies describe a model of triphasic renal injury, consisting of an acute nephrotic phase, a phase of apparent functional and morphologic recovery, and a late phase characterized by recurrent proteinuria and glomerular sclerosis. Severe renal insufficiency and overt nephrotic syndrome differentiate this model from that seen with other PA dosage regimens. When PA is administered by unilateral renal artery perfusion (12) or repeated subcutaneous injections (11, 32-34), modest proteinuria and renal insufficiency are not accompanied by systemic nephrotic syndrome. In this study, massive protein-

Table IV. Effects of Saralasin on Renal Hemodynamics in Phase II

\begin{tabular}{|c|c|c|c|c|c|c|c|c|}
\hline & $\overline{\mathbf{A P}}$ & GFR & RPF & FF & SNGFR & $\mathrm{Q}_{\mathrm{A}}$ & $\overline{\mathbf{P}}_{\text {GC }}$ & $K_{\mathbf{f}}$ \\
\hline & $m m H g$ & \multicolumn{2}{|c|}{$\mathrm{ml} / \mathrm{min}$} & & \multicolumn{2}{|c|}{$n l / \min$} & $m m H g$ & $n l /(s \cdot m m H g)$ \\
\hline \multicolumn{9}{|c|}{ PA + saralasin $(n=5)$} \\
\hline Before & $119 \pm 3$ & $1.22 \pm 0.03$ & $3.90 \pm 0.20$ & $0.32 \pm 0.02$ & $67 \pm 13$ & $270 \pm 44$ & $62 \pm 2$ & $0.055 \pm 0.017$ \\
\hline During & $118 \pm 4$ & $1.49 \pm 0.09$ & $4.60 \pm 0.10$ & $0.32 \pm 0.01$ & $82 \pm 10$ & $314 \pm 34$ & $51 \pm 3$ & $0.162 \pm 0.045$ \\
\hline$P$ value & NS & $<0.05$ & $<0.05$ & NS & $<0.02$ & NS & $<0.005$ & NS \\
\hline \multicolumn{9}{|c|}{ PA + saline vehicle $(n=5)$} \\
\hline Before & $127 \pm 5$ & $1.24 \pm 0.07$ & $4.36 \pm 0.36$ & $0.29 \pm 0.02$ & $65 \pm 9$ & & & \\
\hline During & $131 \pm 4$ & $1.19 \pm 0.08$ & $4.37 \pm 0.24$ & $0.28 \pm 0.03$ & $57 \pm 8$ & & & \\
\hline$P$ value & NS & NS & NS & NS & $<0.05$ & & & \\
\hline
\end{tabular}

Values are means \pm SEM. Abbreviations as in Tables II and III. $P$ values depict differences between before and during saralasin or vehicle. 


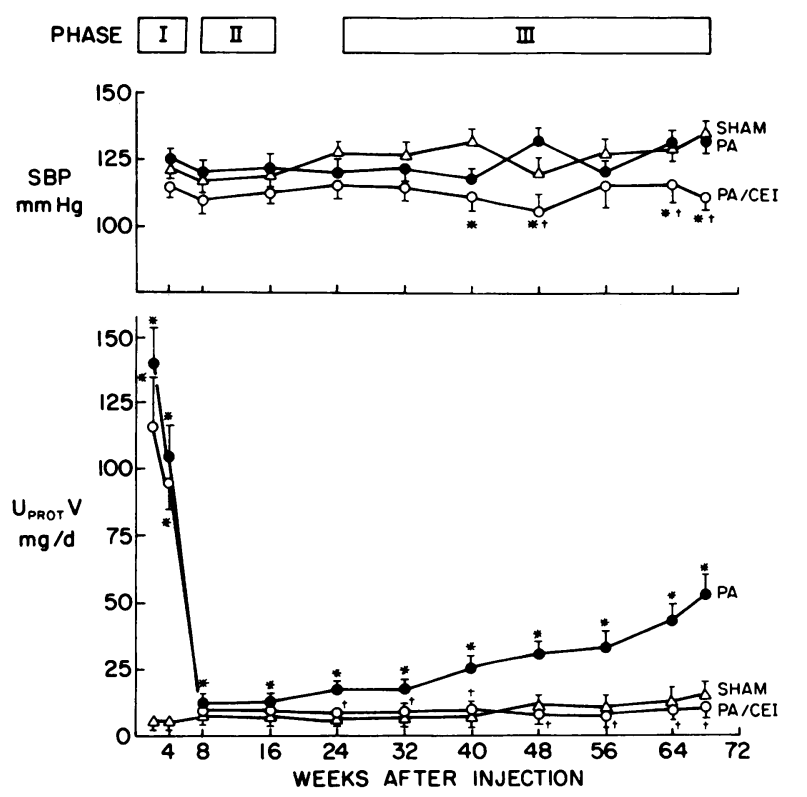

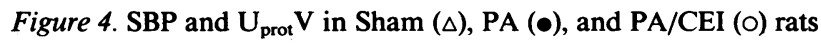
followed for $70 \mathrm{wk}$ after PA or vehicle injection. (Top) Values for SBP in PA rats were comparable to those in sham rats at all time points, whereas concurrent CEI administration (PA/CEI) resulted in values for SBP slightly lower than those seen in the other groups. (Bottom) In phase $I$, the acute nephrotic phase, values for $U_{\text {prot }} V$ were comparably elevated in PA and PA/CEI rats. During phase II, $\mathrm{U}_{\text {prot }} \mathrm{V}$ declined to near normal levels in both groups, though values remained slightly elevated in PA rats. Thereafter, in phase III, values for $U_{\text {prot }} V$ again rose in PA rats, whereas values in PA/CEI rats remained at levels comparable to those in sham rats. Values are means \pm SEM. ${ }^{*} P<0.05$ vs. sham, ${ }^{+} P<0.05$ vs. $P A$ at same time point.

uria was associated with severe renal insufficiency, and other manifestations including edema, ascites, hypercholesterolemia, hypoalbuminemia, sodium avidity, and hypercoagulability, all common features of clinical nephrotic syndromes. This model also differs from that produced by adriamycin, which induces nephrotic syndrome but not severe renal insufficiency $(35,36)$, and from other experimental glomerulonephritides $(13,14)$, which feature renal insufficiency but not nephrotic syndrome. Interestingly, this model also differs from that which occurs using the same PA dosing regimen in Sprague-Dawley rats (1-4), in that the Munich-Wistar rats exhibit markedly more severe renal insufficiency, morphologic injury, and nephrotic syndrome than do the apparently less susceptible Sprague-Dawley rats. Although initial (phase I) and recurrent (phase III) proteinuria and glomerular sclerosis are of comparable magnitude in the two strains, the SpragueDawley rat develops sclerosis much earlier, but with negligible tubulointerstitial abnormalities, suggesting differences in both susceptibility to, and sequellae after, acute injury between the two strains.

As in other models of acute glomerulonephritis $(13,14)$, the primary abnormality leading to depression of SNGFR during the acute nephrotic phase was a marked diminution in $K_{\mathrm{f}}$. This virtually universal manifestation of glomerular injury, which also probably characterizes human glomerulonephritis (37), is variably accompanied by changes in other determinants of SNGFR. Values for $Q_{A}$, which were normal in this study, may be normal or slightly depressed (11-14), but generally do not substantially reduce SNGFR.

Alterations in afferent arteriolar colloid osmotic pressure $\left(\pi_{\mathrm{A}}\right)$ may also modify SNGFR. Values for plasma proteins, particularly albumin, and thus $\pi_{\mathrm{A}}$, were significantly lower in the nephrotic rats. Acutely, reduction of $\pi_{A}$ tends to increase SNGFR, but not to the degree predicted by the Starling relation, because of a concomitant reduction in $K_{\mathrm{f}}(38)$. Accordingly, the severely reduced values for $\pi_{\mathrm{A}}$ in the nephrotic rats in this study may have contributed slightly to preservation of SNGFR, but may have also contributed to the marked depression in $K_{\mathrm{f}}$.

Depression of SNGFR due to a predominant reduction in $K_{\mathrm{f}}$ may be partially offset by a concomitant increase in $\overline{\mathrm{P}}_{\mathrm{GC}}(13$, $14,35,36)$. In contrast to the findings in these other models of experimental glomerulonephritis, however, glomerular capillary hypertension was not found in earlier studies of nonnephrotic models of PA $(11,12)$, nor were values for $\overline{\mathrm{P}}_{\mathrm{GC}}$ substantially elevated in this study. Note, however, that a recent preliminary report indicates that glomerular capillary hypertension may be detected in rats administered PA when studied only $3 \mathrm{~d}$ after injection, before the onset of proteinuria, hypoalbuminemia, and nephrotic syndrome (39). In this study, in the rats in which plasma protein concentration was slightly raised using normal plasma replacement, values for $\overline{\mathbf{P}}_{\mathrm{GC}}$ were modestly but significantly higher than those in sham rats. Finally, acute reduction in $\pi_{\mathrm{A}}$ lowers $\overline{\mathrm{P}}_{\mathrm{GC}}$ in normal rats (38). Together, these observations suggest that acute nephrotic syndrome may result in a transient decrease in $\overline{\mathbf{P}}_{\mathrm{GC}}$, but that glomerular hypertension is present both before and after the relatively brief period of overt nephrotic syndrome.

Concurrent CEI administration had no discernible ameliorative effect on the severity of glomerular injury or nephrotic syndrome induced by PA during phase I. These find-
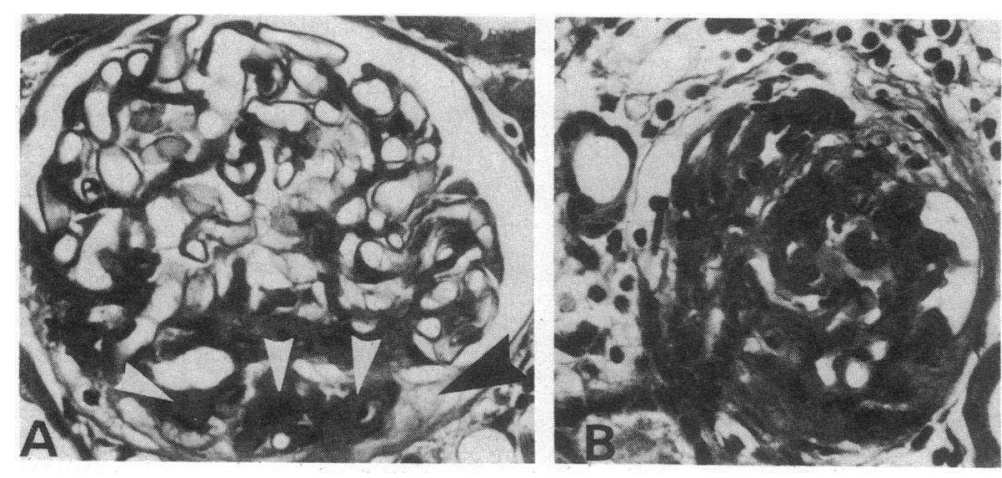

Figure 5. Light micrographs of glomeruli from PA rats at 70 wk. $(A)$ Representative glomerulus from PA rat. Black arrowhead demonstrates segmental area of sclerosis; white arrowheads point to subendothelial hyalinosis lesions (PAS, $\times 540$ ). (B) Globally hyalinized glomerulus from PA rat (PAS, $\times 590)$. 


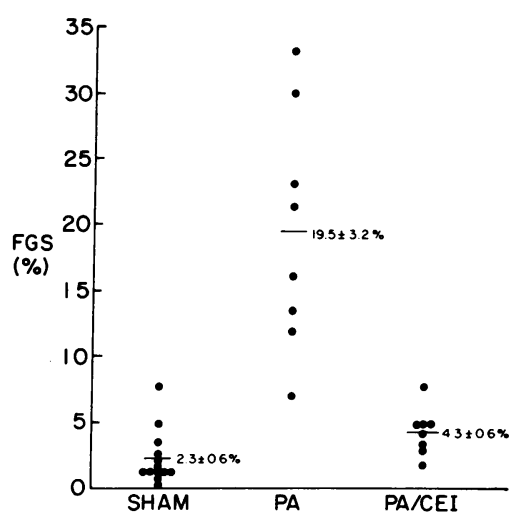

Figure 6. Percentage of glomeruli exhibiting focal and segmental glomerular sclerosis (FGS) in individual rats at 70 wk. Sham rats demonstrated mild degrees of FGS, due to normal aging. Striking FGS was evident in PA rats, whereas values for FGS in PA/CEI rats were comparable to those in sham rats. Values are means \pm SEM.

ings suggest that CEI may exert little intrarenal hemodynamic effect in the absence of systemic or glomerular hypertension. Failure of CEI to substantially reduce nephrotic-range proteinuria has been reported in rats administered either PA (40, $41)$ or adriamycin (35), whereas CEI administration does lower albuminuria in rats rendered nephrotic in passive Heymann nephritis (42). Failure to reduce proteinuria may suggest absence of a hemodynamic effect on capillaries with normal hydraulic pressure, and/or the presence of severe morphologic injury allowing virtually unrestricted passage of macromolecules even at normal hydraulic pressures. These findings contrast with those in other experimental models of glomerular capillary hypertension (8-10), and in patients with renal insufficiency (43) or diabetic nephropathy (44), in which CEI therapy effectively lowers proteinuria.

During phase II, PA rats exhibited spontaneous recovery of renal function, and resolution of most of the morphologic injury and nephrotic syndrome. However, further examination revealed several important abnormalities that may suggest a poor prognosis. Tubulointerstitial injury, including fibrosis, was prominent. This abnormality is frequently found in asso-

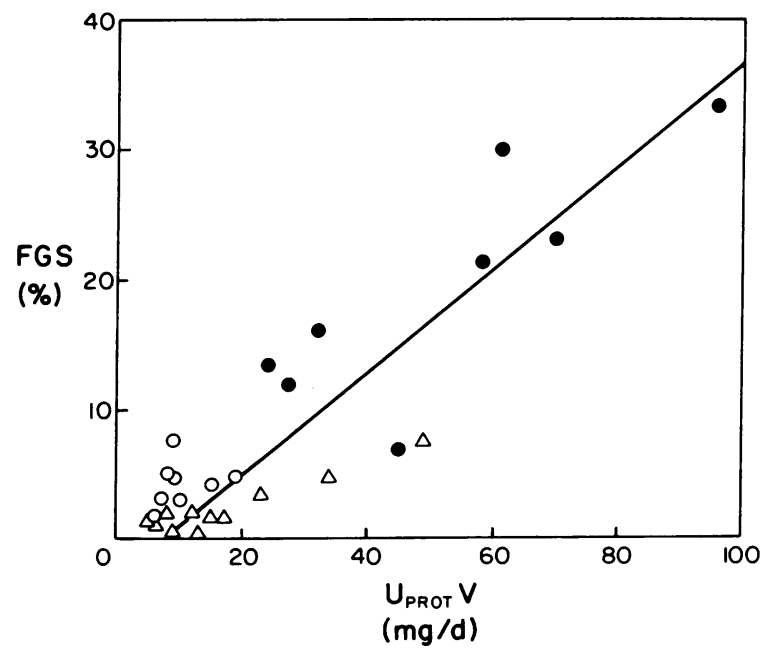

Figure 7. Correlation between urinary protein excretion $\left(\mathrm{U}_{\mathrm{prot}} \mathrm{V}\right)$ and focal glomerular sclerosis (FGS) in sham ( $\triangle$ ), PA (•), and PA/CEI (O) rats at $70 \mathrm{wk}$ after injection. $U_{\text {prot }} \mathrm{V}$ was an accurate predictor of glomerular injury, with a significant correlation between the two parameters $(y=0.347 \mathrm{x}-0.777 ; r=0.90 ; P<0.001)$. ciation with significant glomerular sclerotic injury $(32,45)$, but in this study was prominent long before the relatively late development of glomerular sclerosis.

The most striking abnormality of the apparent recovery period was the marked glomerular capillary hypertension in the PA rats, together with incomplete recovery of values for $K_{\mathrm{f}}$. Finn and Chevalier (46) reported a gradual rise in $\overline{\mathbf{P}}_{\mathrm{GC}}$ after recovery from ischemic acute renal failure in the rat, though values for $\overline{\mathbf{P}}_{\mathrm{GC}}$ were quite low during the period of acute injury, and never exceeded the normal range during the $8 \mathrm{wk}$ of the study. Together, these findings suggest that elevation of $\bar{P}_{\mathrm{GC}}$ may represent a hemodynamic adaptation to a marked reduction in $K_{\mathrm{f}}$ and/or SNGFR, but also that late adaptation to injury may involve an increase in $\overline{\mathbf{P}}_{\mathrm{GC}}$ far above the normal range.

The mechanism whereby acute glomerular injury results in an adaptive but excessive increase in $\overline{\mathrm{P}}_{\mathrm{GC}}$ remains unclear. Conceivably, failure of $K_{\mathrm{f}}$ to return to normal values after resolution of the nephrotic syndrome may reflect ongoing though lessened irreversible structural injury, and elevation of $\overline{\mathrm{P}}_{\mathrm{GC}}$ may reflect a hemodynamic adaptation serving to offset the continued reduction in SNGFR that would otherwise ensue. In contrast to the findings in phase I, CEI had clear beneficial effects during the recovery phase, in that values for $\overline{\mathrm{P}}_{\mathrm{GC}}$ and $K_{\mathrm{f}}$ were normalized. In addition, the saralasin experiments further suggest that intrarenal angiotensin II is an important mediator of these hemodynamic abnormalities. Angiotensin II tends to depress $\mathrm{Q}_{\mathrm{A}}, K_{\mathrm{f}}$, and SNGFR, while raising $\overline{\mathrm{P}}_{\mathrm{GC}}(30,47,48)$. In another model of glomerular capillary hypertension, the partially nephrectomized rat, intravenous infusion of an angiotensin II receptor antagonist failed to reduce $\bar{P}_{G C}(49)$, whereas chronic CEI therapy is well known to normalize $\overline{\mathrm{P}}_{\mathrm{GC}}$ in this model $(8,9)$. In this study, acute saralasin infusion markedly lowered $\overline{\mathrm{P}}_{\mathrm{GC}}$ and increased $K_{\mathrm{f}}$, despite absence of any effect on blood pressure, suggesting a specific intrarenal action. Absence of any effect of the saline vehicle infusion on $\overline{\mathrm{AP}}$ or whole kidney function makes a marked change in intraglomerular hemodynamics very unlikely in this group. Reversal of glomerular capillary hypertension and normalization of $K_{\mathrm{f}}$ with both chronic CEI therapy and acute saralasin infusion thus strongly implicate intrarenal angiotensin II as a hormonal mediator of these hemodynamic abnormalities, though a contributory role of other hormonal mediators cannot be fully excluded.

The long-term studies suggest that the hemodynamic maladaptations in PA rats, though supportive of filtration function in the short term, are in fact responsible for the late development of glomerular sclerosis. That glomerular capillary hypertension contributes to eventual glomerular obsolescence has been suggested by previous studies in which control of glomerular hypertension affords striking morphologic protection in many experimental models $(5-10)$. These findings further support this notion, in that glomerular injury was prominent in the PA rats with sustained glomerular hypertension, and markedly limited in PA/CEI rats in which glomerular hypertension was prevented throughout the long-term studies. Furthermore, they provide new evidence that glomerular capillary hypertension may be a generalized response to acute glomerular injury, and a proximate cause of the later deterioration after apparent recovery. It has been suggested that hemodynamic factors may play an important role in the late progressive renal disease sometimes occurring in patients long 
after an episode of poststreptococcal glomerulonephritis (15). That hemodynamic abnormalities may be present after episodes of acute clinical glomerular injury is further suggested by recent observations that the renal functional response to an acute protein load is impaired in apparently normal post-acute glomerulonephritis patients (50), and that in patients with proliferative lupus nephritis, therapy does not fully restore filtration surface area, resulting in persistent hypofiltration and proteinuria, which may lead to glomerular sclerosis and progressive renal failure even in the absence of continuing immunologic activity (51).

Much recent attention has focused on the possible role of lipids in potentiating glomerular sclerosis $(4,52-54)$. Dietary cholesterol supplementation accelerates development of glomerular sclerosis in this model (4), whereas late proteinuria is substantially ameliorated when serum cholesterol and triglycerides are reduced with cholestyramine (54). It seems likely that as in atherosclerosis, multiple risk factors contribute to glomerular sclerosis. Certain risk factors, such as hypertension, hypercholesterolemia, and platelet aggregation, appear to contribute to both disease processes (55). However, these findings indicate that correction of hemodynamic abnormalities obviates any added risk of ultimate injury that may have resulted from a transient phase of hypercholesterolemia. Note that values for serum cholesterol in PA/CEI rats were even higher than those in PA rats in this study. The significance of this finding is not entirely clear, as clinical studies have established that CEI therapy does not elevate serum cholesterol in humans $(56,57)$. The more severe hypercholesterolemia thus most likely does not reflect any direct effect of CEI administration.

Similarly, the absence of severe late injury (phase III) in PA/CEI rats despite equivalent degrees of early proteinuria (phase I) and interstitial fibrosis (phase II), suggest that neither of these is an invariant predictor of ultimate glomerular sclerosis, as has been previously suggested $(32,58)$, or alternatively, that any added risk from these features may be negated by control of glomerular capillary hemodynamic factors. Increased mesangial macromolecular uptake has been implicated in the pathogenesis of glomerular injury in puromycin nephrosis (59). Of note, angiotensin II infusion increases mesangial uptake in puromycin nephrosis, whereas infusion of saralasin blocks this effect (60). Conceivably, glomerular hypertension perpetuated by enhanced intrarenal angiotensin II activity predisposes to mesangial macromolecular uptake, and control of glomerular hypertension with CEI blocks this pathogenetic mechanism, thereby contributing to the observed protective effect.

Finally, these studies indicate that CEI may control glomerular hypertension in a normotensive model of progressive renal disease, a benefit previously demonstrated in normotensive rats with diabetes mellitus (10). Recent clinical studies indicate that proteinuria may be lessened in normotensive diabetic patients receiving CEI therapy in doses that minimally affect systemic blood pressure (61). These findings suggest that glomerular hypertension and proteinuria may be a common response to renal injury even in the absence of systemic hypertension, and that therapies that control glomerular hypertension are also of benefit in these circumstances. Further studies evaluating dietary and alternative antihypertensive therapies, and potential vasoactive mediators, will prove useful in further elucidating the role of glomerular capillary hyper- tension and its determinants, as well as the relative efficacy of CEI as compared with other therapeutic interventions.

In summary, central venous injection of PA produces a triphasic model of renal injury. During the initial phase, severe nephrotic syndrome is accompanied by renal insufficiency and morphologic injury. Thereafter, nephrotic syndrome spontaneously resolves, but this recovery period is characterized by glomerular capillary hypertension, which is normalized by CEI therapy. In the long term, this hemodynamic maladaptation leads to recurrent proteinuria and glomerular sclerosis, deleterious consequences that are prevented by CEI. Glomerular hypertension thus may explain the late deterioration observed after apparent recovery from acute glomerular injury.

\section{Acknowledgments}

These studies were supported by U. S. Public Health Service grants AM-35930 (Dr. Brenner) and AM-13132 (Dr. Karnovsky). Dr. Anderson was the recipient of an Individual National Research Service Award of the National Institutes of Health (S F32 AM-07206). Additional support was provided by a Clinician-Scientist Award from the American Heart Association (Dr. Diamond), and by a Research Grant-in-Aid from the American Heart Association, Massachusetts Affiliate, No. 13-522-856 (Dr. Diamond and Dr. Anderson). Enalapril was kindly provided by Dr. C. S. Sweet (Merck, Sharp \& Dohme).

\section{References}

1. Diamond, J. R., and M. J. Karnovsky. 1986. Focal and segmental glomerulosclerosis following a single intravenous dose of puromycin aminonucleoside. Am. J. Pathol. 122:481-487.

2. Diamond, J. R., and M. J. Karnovsky. 1986. Nonanticoagulant protective effect of heparin in chronic aminonucleoside nephrosis. Renal Physiol. 9:366-374.

3. Diamond, J. R., and M. J. Karnovsky. 1987. Ameliorative effects of dietary protein restriction in chronic aminonucleoside nephrosis. J. Lab. Clin. Med. 109:538-544.

4. Diamond, J. R., and M. J. Karnovsky. 1987. Exacerbation of chronic aminonucleoside nephrosis by dietary cholesterol supplementation. Kidney Int. 32:671-677.

5. Brenner, B. M., T. W. Meyer, and T. H. Hostetter. 1982. Dietary protein intake and the progressive nature of kidney disease. $N$. Engl. $J$. Med. 307:652-660.

6. Hostetter, T. H., J. L. Olson, H. G. Rennke, M. A. Venkatachalam, and B. M. Brenner. 1981. Hyperfiltration in remnant nephrons: a potentially adverse response to renal ablation. Am. J. Physiol. 241:F85-F93.

7. Hostetter, T. H., J. L. Troy, and B. M. Brenner. 1981. Glomerular hemodynamics in experimental diabetes mellitus. Kidney Int. 19:410-415.

8. Anderson, S., T. W. Meyer, H. G. Rennke, and B. M. Brenner. 1985. Control of glomerular hypertension limits glomerular injury in rats with reduced renal mass. J. Clin. Invest. 76:612-619.

9. Anderson, S., H. G. Rennke, and B. M. Brenner. 1986. Therapeutic advantage of converting enzyme inhibitors in arresting progressive renal disease associated with systemic hypertension in the rat. $J$. Clin. Invest. 77:1993-2000.

10. Zatz, R., B. R. Dunn, T. W. Meyer, S. Anderson, H. G. Rennke, and B. M. Brenner. 1986. Prevention of diabetic glomerulopathy by pharmacological amelioration of glomerular capillary hypertension. J. Clin. Invest. 77:1925-1930.

11. Bohrer, M. P., C. Baylis, C. R. Robertson, and B. M. Brenner. 1977. Mechanisms of the puromycin-induced defects in the transglomerular passage of water and macromolecules. J. Clin. Invest. 60:152-161. 
12. Ichikawa, I., H. G. Rennke, J. R. Hoyer, K. F. Badr, N. Schor, J. L. Troy, C. P. Lechene, and B. M. Brenner. 1983. Role for intrarenal mechanisms in the impaired salt excretion of experimental nephrotic syndrome. J. Clin. Invest. 71:91-103.

13. Maddox, D. A., C. M. Bennett, W. M. Deen, R. J. Glassock, D. Knutson, T. M. Daugharty, and B. M. Brenner. 1975. Determinants of glomerular filtration in experimental glomerulonephritis in the rat. $J$. Clin. Invest. 55:305-318.

14. Ichikawa, I., J. R. Hoyer, M. W. Seiler, and B. M. Brenner. 1982. Mechanism of glomerulotubular balance in the setting of heterogeneous glomerular injury. Preservation of a close functional linkage between individual nephrons and surrounding microvasculature. $J$. Clin. Invest. 69:185-198.

15. Baldwin, D. S. 1982. Chronic glomerulonephritis: nonimmunologic mechanisms of progressive glomerular damage. Kidney Int. 21:109-120.

16. Pfeffer, J. M., M. A. Pfeffer, and E. D. Frohlich. 1971. Validity of an indirect tail-cuff method for determining systolic arterial pressure in unanesthetized normotensive and spontaneously hypertensive rats. J. Lab. Clin. Med. 78:957-962.

17. Maddox, D. A., D. C. Price, and F. C. Rector, Jr. 1977. Effects of surgery on plasma volume and salt and water excretion in rats. Am. J. Physiol. 233:F600-F606.

18. Deen, W. M., J. L. Troy, C. R. Robertson, and B. M. Brenner. 1973. Dynamics of glomerular ultrafiltration in the rat. IV. Determination of the ultrafiltration coefficient. J. Clin. Invest. 52:1500-1508.

19. Mancini, G., A. O. Carbonaro, and J. F. Heremans. 1965. Immunochemical quantitation of antigens by single radial immunodiffusion. Immunochemistry. 2:235-254.

20. Miller, P. L., and T. W. Meyer. 1988. Plasma protein concentration and colloid osmotic pressure in nephrotic rats. Kidney Int. 34:220-223.

21. Jha, R. K. 1975. An improved polychrome staining method for thick epoxy sections. Stain Technol. 51:159-162.

22. Kasten, F. H., and R. Lala. 1975. The Feulgen reaction after glutaraldehyde fixation. Stain Technol. 50:197-201.

23. Vurek, G. C., and S. E. Pegram. 1966. Fluorometric method for the determination of nanogram quantities of inulin. Anal. Biochem. 16:409-419.

24. Führ, J., J. Kacmarczyk, and C. D. Krüttgen. 1955. Eine einfache colorimetrische Methode zur Inulinbestimmung fur Nierenclearance-Untersuchungen bei Stoffwechselgesunden und Diabetikern. Klin. Wochenschr. 33:729-730.

25. Smith, H. W., N. Finkelstein, L. Aliminosa, B. Crawford, and M. Grabor. 1945. Renal clearances of substituted hippuric acid derivatives and other aromatic acids in dog and man. J. Clin. Invest. 24:388-404.

26. Viets, J. W., W. M. Deen, J. L. Troy, and B. M. Brenner. 1978. Determination of serum protein concentration in nanoliter blood samples using florescamine or o-ophthalaldehyde. Anal. Biochem. 88:513-521.

27. Bradley, M., G. B. Schuman, and P. C. J. Ward. 1979. Examination of urine. Todd, Sanford, Davidsohn's Clinical Diagnosis and Management by Laboratory Methods. 16th ed. J. B. Henry, editor. W. B. Saunders Co., Philadelphia, PA. 604-605.

28. Wallenstein, S., C. L. Zucker, and J. L. Fleiss. 1980. Some statistical methods useful in circulation research. Circ. Res. 47:1-9.

29. Ryan, G. B., and M. J. Karnovsky. 1975. An ultrastructural study of the mechanisms of proteinuria in aminonucleoside nephrosis. Kidney Int. 8:219-232.

30. Blantz, R. C., K. S. Konnen, and B. J. Tucker. 1976. Angiotensin II effects upon the glomerular microcirculation and ultrafiltration coefficient of the rat. J. Clin. Invest. 57:419-434.

31. Corman, B., and J. B. Michel. 1986. Renin-angiotensin system, converting enzyme inhibition, and kidney function in aging female rats. Am. J. Physiol. 251:R450-R455.

32. Glasser, R. J., J. A. Velosa, and A. F. Michaels. 1977. Experi- mental model of focal sclerosis. I. Relationship to protein excretion in aminonucleoside nephrosis. Lab. Invest. 36:519-526.

33. Velosa, J. A., R. J. Glasser, T. E. Nevins, and A. F. Michael. 1977. Experimental model of focal sclerosis. II. Correlation with immunopathologic changes, macromolecular kinetics, and polyanion loss. Lab. Invest. 36:527-534.

34. Grond, J., J. J. Weening, and J. D. Elema. 1984. Glomerular sclerosis in nephrotic rats. Comparison of the long-term effects of adriamycin and aminonucleoside. Lab. Invest. 51:277-285.

35. Meyer, T. W., and H. G. Rennke. 1986. Nephron loss increases the glomerular permeability defect in nephrotic rats. Clin. Res. 34:699a. (Abstr.).

36. O’Donnell, M. P., L. Michels, B. Kasiske, L. Raij, and W. F. Keane. 1985. Adriamycin-induced chronic proteinuria: a structural and functional study. J. Lab. Clin. Med. 106:62-67.

37. Myers, B. D., T. B. Okarma, S. Friedman, C. Bridges, J. Ross, S. Asseff, and W. M. Deen. 1982. Mechanisms of proteinuria in human glomerulonephritis. J. Clin. Invest. 70:732-746.

38. Baylis, C., I. Ichikawa, W. T. Willis, C. B. Wilson, and B. M. Brenner. 1977. Dynamics of glomerular ultrafiltration. IX. Effects of plasma protein concentration. Am. J. Physiol. 232:F58-F71.

39. Gabbai, F. B., N. Bobadilla, E. Tapia, C. Calleja, L. Romero, and J. Herrera-Acosta. 1988. Glomerular hemodynamics response to puromycin aminonucleoside before the appearance of proteinuria. Kidney Int. 33:410 (Abstr.)

40. Chiu, P. J. S., and A. D. Brown. 1981. Effect of captopril on pre-existing and aminonucleoside-induced proteinuria in spontaneously hypertensive rats. Res. Commun. Chem. Pathol. Pharmacol. 31:419-433.

41. Marinides, G. N., G. C. Groggel, A. H. Cohen, T. Cook, R. L. Baranowski, C. Westenfelder, and W. A. Border. 1987. Failure of angiotensin converting enzyme inhibition to affect the course of chronic puromycin aminonucleoside nephropathy. Am. J. Pathol. 129:394-401.

42. Hutchison, F. N., M. Schambelan, and G. A. Kaysen. 1987. Modulation of albuminuria by dietary protein and converting enzyme inhibition. Am. J. Physiol. 253:F719-F725.

43. Heeg, J. E., P. E. de Jong, G. K. van der Hem, and D. de Zeeuw. 1987. Reduction of proteinuria by angiotensin converting enzyme inhibition. Kidney Int. 32:78-83.

44. Hommel, E., H.-H. Parving, E. Mathiesen, B. Edsberg, M. D. Nielsen, and J. Giese. 1986. Effect of captopril on kidney function in insulin-dependent diabetic patients with nephropathy. Br. Med. $J$. 293:467-470.

45. El Nahas, A. M., S. N. Zoob, D. J. Evans, and A. J. Rees. 1987. Chronic renal failure after nephrotoxic nephritis in rats: contributions to progression. Kidney Int. 32:173-180.

46. Finn, W. F., and R. L. Chevalier. 1979. Recovery from postischemic acute renal failure in the rat. Kidney Int. 16:113-123.

47. Myers, B. D., W. M. Deen, and B. M. Brenner. 1975. Effects of norepinephrine and angiotensin II on the determinants of glomerular ultrafiltration and proximal tubule fluid reabsorption in the rat. Circ. Res. 37:101-110.

48. Ichikawa, I., J. F. Miele, and B. M. Brenner. 1979. Reversal of renal cortical actions of angiotensin II by verapamil and manganese. Kidney Int. 16:137-147.

49. Scholey, J. W., and T. W. Meyer. 1988. Acute blockade of angiotensin II activity does not reproduce the effect of converting enzyme inhibition in rats with reduced renal mass. Kidney Int. 33:384 (Abstr.)

50. Rodriguez-Iturbe, B., J. Herrera, and R. Garcia. 1985. Response to acute protein load in kidney donors and in apparently normal postacute glomerulonephritis patients: evidence for glomerular hyperfiltration. Lancet. ii:461-464.

51. Kiberd, B. A., S. Strober, and B. D. Myers. 1987. Outcome of acute glomerular injury in proliferative lupus nephritis. Clin. Res. 35:635 (Abstr.) 
52. Moorhead, J. F., M. K. Chan, and Z. Varghese. 1986. The role of abnormalities of lipid metabolism in the progression of renal disease. In The Progressive Nature of Renal Disease. W. E. Mitch, B. M. Brenner, and J. H. Stein, editors. Churchill-Livingstone, Inc., New York. 133-148.

53. Grond, J., H. van Goor, and J. D. Elema. 1986. Histochemical analysis of focal segmental hyalinosis and sclerosis lesions in various rat models of experimental nephrotic syndrome. Kidney Int. 29:945 (Abstr.)

54. Hanchak, N. A., M. J. Karnovsky, and J. R. Diamond. 1988. Cholestyramine resin lowers acute and recurrent proteinuria in chronic puromycin aminonucleoside nephrosis. Kidney Int. 33:376 (Abstr.)

55. Diamond, J. R., and M. J. Karnovsky. 1988. Focal and segmental glomerular sclerosis: analogies to atherosclerosis. Kidney Int. 33:917-924.

56. Moncloa, F., J. A. Sromovsky, J. F. Walker, and R. O. Davies.
1983. Enalapril in hypertension and congestive heart failure: overall review of efficacy and safety. Drugs. 30 (Suppl. 1):82-89.

57. Weinberger, M. H. 1985. Antihypertensive therapy and lipids: evidence, mechanisms, and implications. Arch. Intern. Med. 145:1102-1105.

58. Bertani, T., F. Cutillo, C. Zoja, M. Broggini, and G. Remuzzi. 1986. Tubulo-interstitial lesions mediate renal damage in adriamycin glomerulopathy. Kidney Int. 30:488-496.

59. Grond, J., J. Koudstaal, and J. D. Elema. 1985. Mesangial function and glomerular sclerosis in rats with aminonucleoside nephrosis. Kidney Int. 27:405-410.

60. Keane, W. F., and L. Raij. 1985. Relationship among altered glomerular barrier permselectivity, angiotensin II, and mesangial uptake of macromolecules. Lab. Invest. 52:599-604.

61. Marre, M., H. Leblanc, L. Suarez, T.-T. Guyenne, J. Menard, and P. Passa. 1987. Converting enzyme inhibition and kidney function in normotensive diabetic patients with persistent microalbuminuria. Br. Med. J. 294:1448-1452. 